\section{TRAPPING BIG GAME OF THE BEA.}

\section{ORARLRS F. HOWDRB.}

The relative intelligence of many large sea animals can be judged or tested to a certain extent by an examination of their methods of escaping from the various traps and devices set for their capture. On the northern coast of Norway and on some of the islands off this coast, the fishermen derive a large yearly harvest from the capture of whales of various kinds, which stray into the harbors. At certain localities where the bays are almost landlocked lofty stands are erected, similar to the otter outlooks on the North Pacific, and when a school is sighted, scores of boats put out, and by the very simple process of driving, hundreds of valuable oil-producing cetaceans are en. trapped. The boats are formed in a line behind them, and by shouting, beating on the woodwork with clubs, and moving slowly in, the school or herd is completely demoralized, and finally driven high upon the beach.

The Faroe Islands are famous for this method of whaling, the so-called (locally) grind whale being popular game. One year a school of two hundred were caught at Tor Bay, and at F'etlar, one of the Shetland Islands, one hundred and ninety were taken in this simple manner, while a herd of five hundred was driven ashore by a crowd of boatmen in Uyea Sound in Unst. One of the largest catches ever made was in Hvalfiord, Iceland, where eleven hundred were driven ashore. The Mercury, a Scottish paper, thus describes a catch: "I he little town of Stornaway was lately enlivened by a scene of the most animating and striking description. An immense shoal of whales was, early in the morning, chased to the mouth of the har cor by two fishing boats which had met them in the offing. This circumstance was immediately descried from the shore, and a host of boats, about thirty or forty in number, armed with every species of w'eapon, set off to join the others in pursuit, and engage in combat with these giants of the deep. The chase soon became one of bustle and anxiety on the part of both man and whale. The boats were arranged by their crews in the form of a crescent, in the fold of which the whales were collected and where they had to encounter tremendous showers of stones, splashing $s$ ot oars, frequent gashes with harpoons and spears, while the din create by the shouts of the boats' crews and the multitude on shore was in itself sufficient to stupefy and stum the bottle-nosed foe to surrender. the bottle-nosed foe ion, how ever, the floating phalanx was broken, and it required the greatest activity and tact ere the breach could be repaired and the fugitives regained. 'Ine shore was neared by degrees, the boats advancing and retreating by turns, till at length they succeeded in driving the captive monsters on the beach opposite the town and within a few yards of it. The movements of the whales were now violent, but except when one became unmanageable and enraged when harpooned, or his tail fixed in a noose, the were not dangerous to approach. were not dangerous to approach. In a few hours the whales wer with the dead carcasses, while the sea presented a bloody and troubled aspect, giving evident proof that it was with no small effort that they were subdued and made the property of man. On the pres ent occasion, the whole inhabitant of the place, male and female, wer interested spectators of the scene."

Such scenes are not uncommon in America, and in one of the accompanying photographs is shown a large school of blackfish which were captured in one of the bestarranged natural traps in this country-the little bay forming the harbor of Provincetown, Cape Cod. On the map the exact situation is seen. The blackfish or whales come down the coast from the north, encounter shallow water possibly to the east of Plymouth or midway the Cape, then follow it along, and are nat urally led into the cul de sac of Cape Cod Harbor. Here the boats easily surround and drive the whales in. The large catch pictured created great excitement, even in a place where fishing is the order o the day and large catches are familiar to everyone. The school was sighted in the outer bay at North Truro at first, and a general alarm being given, ever available boat and dory put out, the fleet easily placing itself in the rear, and while the blackfish were inside the point the actual charge began; men rowing shouting, and screaming; some pounding the gunwales with oars; others striking the water, all cryin at the top of their voices-a babel made up of Cape Cod, Portuguese, Swedish, and other tongues that doubtless filled the hearts of the blackfish with terror as they swam on and were literally driven upon the sands.

It was then that the most remarkable scene ensued. The boats pressed in from the bay, the occupants now striking the huge creatures with oars, harpoons, an lances, leaping overboard at the risk of their lives,

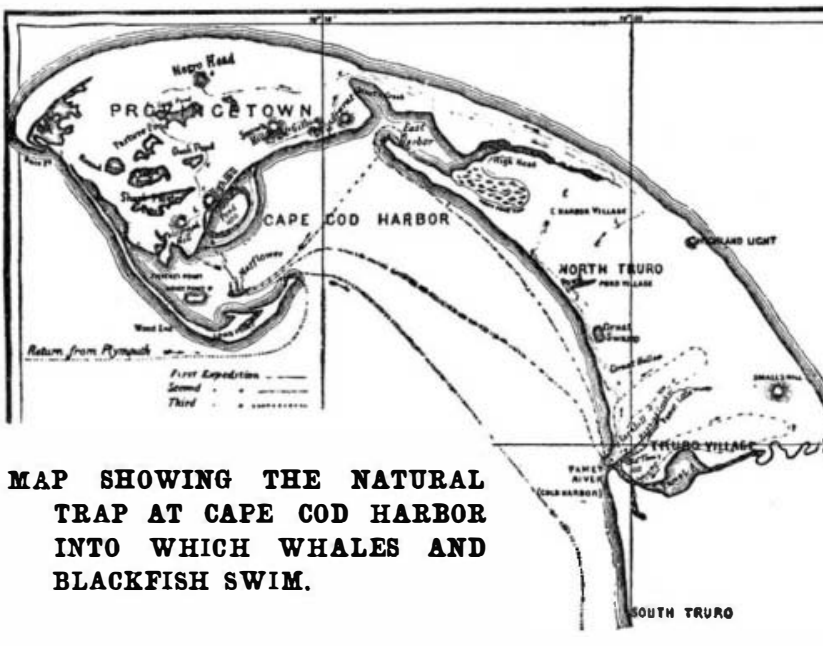

while down the beach came an army from the lan from Truro and Provincetown, some in wagons, many on foot, others on horseback, armed with harpoons, guns, and even scythes. These joined the throng, and the remarkable sight was witnessed of cetaceans being lanced by men on horseback, the animals bein driven out into the shallows, where for a few moment a scene of carnage was enacted that has few equal in the annals of blackfishing. Everyone was anxious to obtain a share, and various methods were devised to make legal claims. Some left their knives in the fish they claimed; others quickly cut their initials in the black hide, while the small members of a family

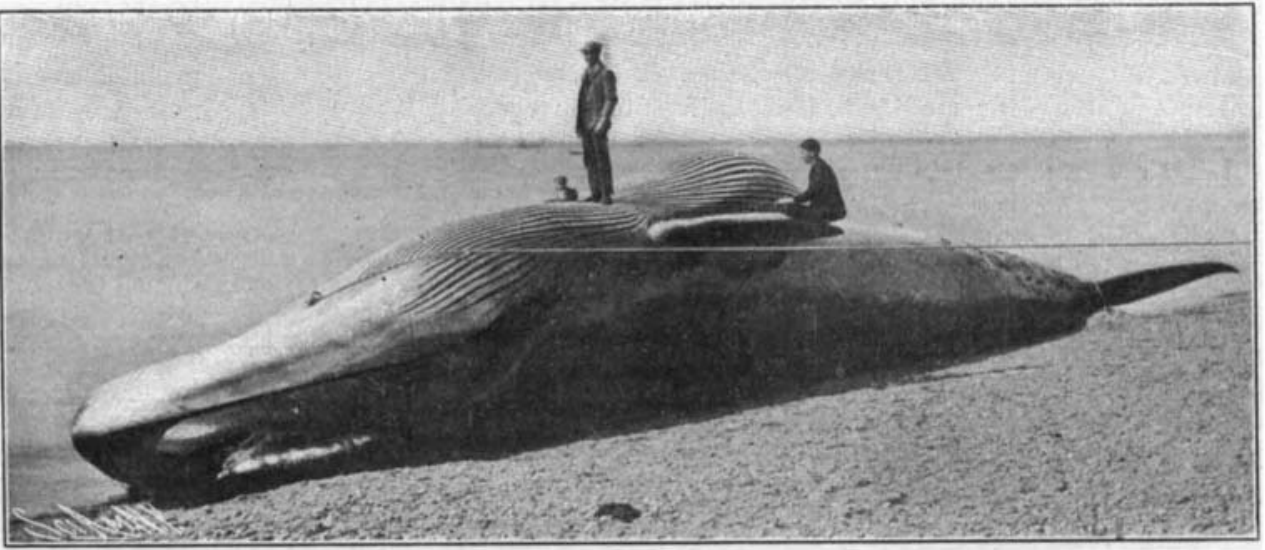

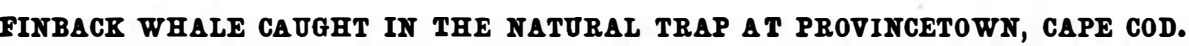

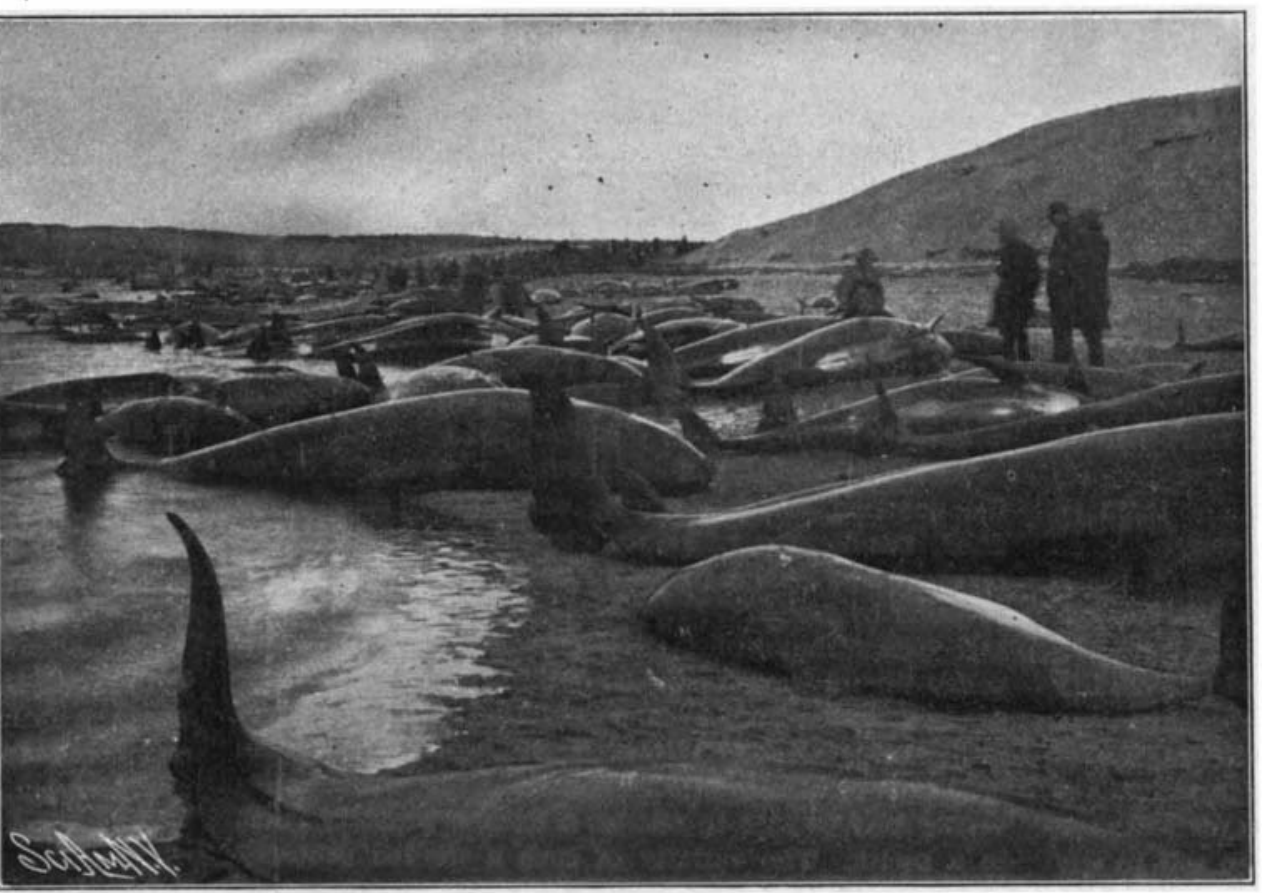

MACRFISH CAUGHT IN THE NATURAL TRAP AT PROVINCETOWN, CAPE COD. dollars was the net profit of the catch, divided among large number of persons.

Larger game than the blackfish finds its way into is natural trap, as shown by the excellent photo列 to this trap wander inshore, encounter the arm of the Cape reaching out into the sea-one of the most remarkable results of currents in the world-and are led along into the bay. Many of the predaceous cetaceans chase food of various kinds inshore, and so bewander in. The one here shown was first observed at the entrance of the bay, and was driven in by attacks rom the occupants of many boats. The whale made many efforts to regain deep water, displaying much intelligence; but it finally became confused and ran aground, where it was presently dispatched by the men, who secured it with ropes and hauled it in, so that at low tide it was entirely above water, where as cut up and the valuable portions appropriated.

While Provincetown is a natural trap, its shores are lined with the peculiar nets of the local fishermen. These have the appearance of brush fences, which they are-literal runways leading the unsuspecting net. The writer joined the owners of such a net in nother locality, and when the net was lifted to the surface the variety of game was remarkable, including nearly every kind of fish found in adjacent waters. These nets at Cape Cod are frequently the means of taking giant horse mackerel. The latter swim into the harbor in schools after food, or are chased in by orca-their inveterate enemy-and become entangled; and if they do not wreck the entire trap, they are often caught. This great fish doubtless is 'very cunning, as individuals have been known to enter a pound and devour its available contents, then escape to repeat the trick, to the consternation of the fisher man; but, as a rule, the large game becomes entaned and is captured.

On the coast of California, at the island of Santa Catalina, there is a singular fjord or deep harbor which has formed a trap for many large marine animals from cetaceans to sail-fishes. The cut is called Santa Catalina Harbor, and runs directly into the island, dividing a low mountain ridge, almost severing it; in fact, there is good reason to believe that at one time there were two islands, the intermediate space having been filled in, in the passage of time. This deep cut affords an interesting highway for large game, which is attacked by the fishermen who live in the vicinity, and easily. caught. The writer has seen several large swordfishes which were entrapped here. The locality is particularly interesting from being the site o a herd of sea elephants, which were exterminated during the time of Scoresby in the early fifties.

The Value of Food to Life.

Prof. R. H. Chittenden, director of the Sheffield Scientific School, will co-operate with the Sheffield Laboratory in a physiological study of the minimum amount of proteid or albuminous food required for the maintenance of health and strength under ordinary conditions of life. In this study there are no specia theories involved and no special systems of dietetics, but the object especially aimed at is to ascertain experimentally whether physiological economy in diet cannot be practised with distinct betterment to the body and without loss of strength and vigor. There is apparently no question that people ordinarily consume much more food than there is any real necessity for, and that this excess of food is in the long run detrimental to health and defeat the very objects aimed at. It is with a view to gather as many facts as possible on this subject that the

whose head had killed several, mounted the bodies study in question is undertaken

At the end of the run the great beach and the shallows were strewn with the huge black and shapely forms of the fish which at a distance resembled small whales; and as the tide went out, the sand appeared to be covered with countless numbers, extending far down the shore and out into the bay. This windfall was a month's sensation on Cape Cod, and for weeks the fishermen along shore tried out the oil. It was estimated that between twenty and thirty thousand pioneer ship and engine builder of Buffalo, N. Y. He was 85 years old at the time of his demise. He cam twenty years had built one of the largest plants in this country at the time. In 1866 the works presided over by him achieved the notable distinction of turning out four locomotives which were then the largest in the world.
Among the recent deaths noted is that of David Bell, to this country from Scotland in 1842 , and in about 